\title{
QUANDO O ANIMAL DURA MAIS QUE A ESTIMAÇÃO
}

Jean Segata

O estudo das relações humano-animal tem ganhado boa expressão na antropologia contemporânea. Ele forma um campo que se desenvolve a partir de duas frentes de discussão que se complementam - uma política e outra epistemológica. A primeira envolve ativismos e novos movimentos sociais em torno de direitos e de moralidades dos animais, enquanto a outra passa a questionar e a reposicionar qualidades e distinções entre eles e os humanos. ${ }^{1}$ Particularmente, minha inserção nesse campo se deu por meio de pet shops e de clínicas veterinárias do sul do Brasil, que formaram o cenário etnográfico pesquisado entre 2007 e 2012. A partir dele, eu procurei mostrar que a medicalização de estados físicos e morais e as práticas de produção de longevidade para animais têm sido facilitadas pelo alto investimento em tecnologias, como equipamentos, diagnósticos, intervenções cirúrgicas, procedimentos clínicos e um vasto mercado que congrega medicamentos e outros dispositivos que definem saúde, doença e estética a partir de modelos biomédicos da medicina humana e sua infraestrutura global (Segata 2012).

O meu interesse pelo tema está associado ao redimensionamento que o debate sobre natureza e cultura ganhou nos últimos anos. Se essa antinomia ainda resiste como um programa de controle desde o pensamento antropológico moderno, para mim, ela encontra na relação humano-animal uma figura de mediação. Em linhas gerais, esta ideia forma o pano de fundo do que tratarei aqui, concentrando-me nas controvérsias em torno do envelhecimento de um animal de estimação e da manutenção de seu vínculo com os seus companheiros humanos. A situação etnográfica que me guia é a de que, mais velhos, alguns desses animais têm desenvolvido problemas que até há pouco tempo não faziam parte do repertório veterinário e nem dos seus companheiros humanos, como é o caso dos cânceres e tumores, das cegueiras, dos problemas renais e hepáticos, da hipertensão, da depressão, entre outros. Como esses diagnósticos e tratamentos são contínuos àqueles dos humanos, uma forma particular de identificação e de relação com o animal em meios urbanos, especialmente em clínicas veterinárias, parece 
ser produzida na conjugação entre a partilha de elementos valorizados entre nós como cultura - como nomes humanos, roupas, direitos e moralidades - e aqueles pensados como natureza - como a universalidade da fisiologia animal e a medicalização dos seus desvios.

Contudo, parece que longevidade e envelhecimento não coincidem, já que viver mais, mas sem condições de preservar a autonomia, é um tipo de custo que muitas vezes não está incluído no cálculo das intervenções para prolongamento da vida (e que, em alguns casos, se torna um prolongamento da morte). ${ }^{2}$ Animais velhos e doentes tornam-se parte de um dilema moral, entre a escolha em levar adiante "tratamentos complicados" ou seu encaminhamento para a eutanásia - em alguns casos, ainda, resulta disso o abandono desses animais nas ruas. O caso de Belinha, descrito a seguir, ajuda a mostrar as camadas de complexidade envolvidas nessas questões em que a fisicalidade e a moralidade são mobilizadas de forma contingente, tanto para equivaler e diferenciar humanos e animais como para compor e decompor um animal de estimação. ${ }^{3}$

\section{O sacrifício de Belinha}

"Ainda podemos aproveitar muita coisa". Foi assim que Marcos apresentou-me Belinha. Tratava-se de uma cadela de bom porte, fruto de cruzamentos pouco definidos, entre os quais se sobressaiu a aparência de uma poodle gigante com cerca de $60 \mathrm{~cm}$ desde a cernelha. A pelagem encaracolada, característica da raça, variava do tom pérola ao cinza claro, mas rareava em boa parte do corpo denunciando-a na idade avançada e nos problemas de saúde. Havia dois anos que seus ossos a faziam padecer.

Marcos, médico veterinário, recebeu-me durante mais de um ano em sua loja de animais, no interior de Santa Catarina. Impulsionado pela especulação imobiliária, o lugar mimetizou um estilo de vida característico das novas cidades, centrando-se na valorização da imagem dos grandes condomínios verticais como símbolo de praticidade, segurança e desenvolvimento individual. Foi nessa mudança de paisagem do interior brasileiro que Belinha se tornou moradora de um pequeno apartamento de dois quartos, onde partilhou mais de uma década de sua vida com uma família humana. Ali, cresceu com um jovem casal de profissionais liberais e acompanhou a chegada de seus filhos, fez parte da foto emoldurada na sala e brincou com todos, mas aprendeu a ficar só e a esperar pelos rápidos passeios de fim de tarde, depois que seus humanos chegavam da "correria da vida moderna". 
"Foram dez anos de muita alegria, de muita coisa boa juntos", resumiu Paula, ao repetir para mim a história que lhe haviam contado ao trazerem a cadela até a clínica que funcionava na loja. A jovem veterinária, filha de Marcos, explicou-me que Belinha havia sido diagnosticada com mais uma fissura de ossos, agora em duas costelas do lado esquerdo do tronco. No apartamento em que vivia, havia um degrau entre o corredor e a sala de estar e, como ela já não caminhava mais com tanta jovialidade e segurança, acabou caindo de lado e se ferindo. A dificuldade de locomoção vinha, sobretudo, da calcificação de algumas vértebras, que lhe provocavam desvios na coluna e dores constantes, além das fraturas mal recuperadas de suas patas que tornavam a sua condição de vida insustentável.

Fazia pouco tempo que eu estava em campo, mas àquela altura começava a se materializar a queixa frequente de Marcos e de Paula de que muita gente não quer "se incomodar" quando o cão começa a ficar velho - aliás, como diziam, "muita gente não gosta de velho, seja bicho, seja o que for. Pois tudo é muito bom enquanto se está com saúde e se tem como dar conta de si próprio". Mesmo com os suplementos de fósforo, cálcio ou vitamina $\mathrm{D}$, Belinha já somava fraturas que teimavam em não se recompor. E não era só isso, a idade de 12 anos impunha-lhe outras complicações, como uma ligeira cegueira e a surdez parcial.

O quadro de Belinha era tocante, mas não poderia ser descrito como uma exceção entre cães nessa idade, principalmente desde a emergência de dispositivos que têm prolongado a sua vida. Mas logo ela, que era uma tão singular companhia, e que agora se arrastava pela casa, já sem muito pelo na parte traseira do corpo, onde acumulava escaras por não conseguir se levantar com frequência. Belinha era a infeliz imagem de uma "judiaria", como eles se lamentavam aos veterinários. Contudo, mesmo que sem poder andar e num visível esforço de sobrevida, "ela ainda tinha um sangue muito bom, apesar dos ossos ruins", explicou-me Marcos. E esta era a razão de eu tê-la encontrado preservada no fundo da loja com outros dois "vira-latas", que foram recolhidos da rua. Depois de ser pet por mais de dez anos, Belinha tornou-se parte do estoque de sangue da clínica veterinária.

Paula sempre insistia para eu notar como era comum que as pessoas fizessem de seus animais uma espécie de "bicho de pelúcia vivo". E, em grande medida, esse foi o caso da Belinha: boa, até seus donos acharem mais vantajoso sair da loja com um animal novo e deixá-la para a morte. Eles decidiram empregar o dinheiro num filhote de Beagle ao invés de tratar aquele cão descaracterizado pela osteodistrofia e os demais efeitos de uma vida longa. Osteodistrofia, palavra que significa "osso mal alimentado", é um termo médico generalizado entre a medicina humana e a veterinária e designa um conjunto de anormalidades de desenvolvimento do tecido ósseo (Carfioci \& Jeremias 2010; Carfioci 2014). 
Essas anormalidades podem ser classificadas em oesteomegalias (muito osso) e osteopenias (pouco osso). As primeiras, em geral, têm causa genética e se caracterizam pela assimetria resultante da assincronia do crescimento dos ossos - o que no caso veterinário é identificado em algumas raças de porte grande, por exemplo, o Rottweiller, o Dogue Alemão ou os cães retrievers, como o Golden e o Labrador. Já as osteopenias possuem subclasses, como a osteoporose, que é causada por uma desnutrição proteica que reduz a produção do osteoide (a porção mineralizada do tecido ósseo). Além dela, há o raquitismo, que aparece com alguma raridade em filhotes com baixa mineralização do osteoide por carência de vitamina D. No entanto, uma das variantes mais comuns entre as osteopenias é a oesteodistrofia fibrosa ou hiperparatireoidismo nutricional secundário, cuja principal característica morfopatogênica é a desminelarização causada pela retirada ativa de cálcio dos ossos, que se tornam facilmente quebradiços (Carfioci 2014). Essencialmente, sua prevalência é explicada por causas nutricionais e este era, em particular, o caso de Belinha.

Faz algum tempo que a literatura veterinária é bastante unânime em atribuir à má alimentação dos animais a maior parte dos seus problemas (Carfioci \& Jeremias 2010). No passado, por exemplo, o mal que acometia Belinha era explicado como uma consequência de dietas que empregavam comidas caseiras mal balanceadas, com carnes temperadas e com massas à base de farinha branca, que sobravam da mesa dos humanos. Essa fonte de alimento responderia por pouco mais de $30 \%$ da necessidade de cálcio dos cães - além de ser preparada com ingredientes com alta quantidade de sódio que resulta do uso de sal e outras substâncias que provocam males mais acentuados no organismo desses animais, como a constipação e os problemas renais.

Na antropologia, Kulick (2009) analisou esse cenário dietético dos animais de estimação. Segundo ele, há pouco mais de um século, a indústria de alimentos se esforçou para criar uma demanda por meio de afirmações de que essas sobras da mesa e outras comidas com as quais os animais sempre tinham se alimentado não eram tão boas quanto aquelas industrializadas, vendidas sob a forma de rações. Calculadas para os animais, as rações deveriam favorecer sua saúde e desenvolvimento, mas depois de algumas décadas, este tipo de alimentação passou a protagonizar novos problemas, como aqueles que envolvem animais gordos, como analisado por ele. Em resposta, o novo negócio é o desenvolvimento de alimentos tipo Premium, que possuem fórmulas especiais para etapas da vida ou para animais em dietas, já que a sua obesidade é hoje tomada como uma crise. Por outro lado, animais "gorduchos", até pouco tempo muito valorizados por sua "fofura", têm sido vistos como doentes e sofredores, mobilizando os meios de comunicação de massa, a opinião pública ou as organizações de proteção animal. 
Além disso, com o atual comércio de alimentos "bem calculados", problemas nos ossos e com o peso tenderiam a rarear, não fosse o caso de produtos de má qualidade manufaturados em longa escala em favor de um baixo preço para o consumidor final ou pelo emprego equivocado de suas indicações. Como me explicava Marcos, um exemplo comum é o do excessivo uso de rações indicadas para crescimento entre aqueles que querem tornar seus animais maiores e "mais fofos"; e como analisou Kulick (2009), o que era lido como fenômeno trivial, ou preferência estética, passou a ser tomado como problema social, culminando em decisões judiciais favoráveis ao afastamento desses animais do convívio com os humanos, ou mesmo no desfecho de seu sacrifício. Tornar um animal gordo é um negócio para o segmento pet e, na filosofia de alguns movimentos protecionistas, isto é visto como algo mais cruel do que levá-lo à morte.

Belinha não era, de um ponto de vista técnico, uma cadela gorda. Marcos mostrou-me isso por meio de gráficos de medida padrão. Havia certo equilíbrio entre sua altura e sua massa, ainda que o "bom porte" ou "entroncada" e "massuda" - termos com os quais o veterinário fazia referência a ela - deixavam claro que não se tratava de uma cadela propriamente magra. Contudo, o fato de ela ser "bem forte", como ele insistia, não veio à custa de treinamentos físicos e nem de boa nutrição. Sua massa era o resultado de um sedentarismo compulsório, já que ela não podia mais andar em razão de suas patas quebradas em consequência da doença nos ossos. Viver naquelas condições era uma crueldade do ponto de vista de seus companheiros humanos e isto justificava sua morte, provocada pelo sacrifício.

Na loja de Marcos, a ideia de sacrifício não era uma questão confortável. Em termos diretos, tal sacrifício reduzia-se a uma solução para o sofrimento de animais e de seus companheiros humanos. Mas era um tema tratado com muitas reservas. O próprio termo "sacrifício" era censurado, já que Marcos me reprovava cada vez que eu o utilizava, ao invés de eutanásia. "Aqui, na clínica", dizia-me ele, "ninguém sacrifica ninguém - o que fazemos é um procedimento regularizado pelos conselhos e pela literatura veterinária a partir de um diagnóstico final ou irreversível, ou seja, trata-se de uma eutanásia e não de uma morte gratuita".

Marcos deslocava o problema moral em torno da morte de um animal para a seara da técnica. Evidentemente, ele nutria uma crença sobre a ideia de sacrifício que não era concebida como algo que se pudesse pensar como alguma função social valorizada, como no tipo de análise que difusamente percorre a história moderna da antropologia, especialmente desde Mauss e Hubert (2005). O sacrifício-dádiva, o sacrifício-alimento ou o sacrifíciocontrato, analisados por estes autores sob a forma de um dispositivo relacional 
e simbólico, formaram chaves de compreensão sobre a prescrição da ação e a natureza da representação como constituintes do que para eles era o seu objeto excelente, o social. Mas no léxico pragmático de Marcos, sacrificar era sinônimo de uma morte por si mesma, banalizada, sem fins ou justificativas reconhecíveis - o que a equiparava à semântica da violência.

Na clínica, sacrificar significava morte inútil, pois, como me dizia o veterinário: "mata-se um animal em autodefesa, mata-se para comer ou para se tirar proveito de partes - carne, couro, chifres, dentes" - e Belinha não tinha o que oferecer se fosse morta. A propósito, este foi o seu argumento defensivo quando viveu um embaraço com os companheiros humanos da cadela, que alguns meses depois de a deixarem na clínica souberam que ele não havia feito a eutanásia. Uma das crianças, mais apegada a Belinha, ainda não reagia bem ao luto e saber que ela estava viva deixou-a confusa e querendo reavê-la. Em resposta, Marcos produziu uma analogia com situações humanas, em que os corpos são mantidos vivos sob condições especiais durante algum tempo, a fim de se aproveitarem órgãos transplantáveis. Ele sugeriu que Belinha não sobreviveria fora daquele contexto de cuidados e que, acima de tudo, ali ela ajudaria outros animais em situação de emergência. Conforme o veterinário, doar parte de si era o compromisso social de Belinha.

Assim, matar ou manter viva a cadela era, conforme cada registro, um ato de violência ou de altruísmo. Tratava-se de uma questão de foco - de partes ou do todo. Belinha, como ser, não podia sofrer, mas suas partes, como substâncias, não podiam ser desperdiçadas. Se suas patas quebradas a faziam sofrer gratuitamente, Marcos encontrou uma utilidade para essa dor, pois a prestação sacrificial da cadela não se realizava com sua morte, mas com sua vida. Esse emprego de Belinha ou da parte dela que o veterinário considerava saudável - o sangue e a forma como ele era consumido na clínica veterinária - gerou algumas manifestações de desconforto entre pessoas ligadas à proteção animal. O seu caso era considerado emblemático para pensar a violência contra os animais. ${ }^{4}$

\section{A moral naturalista}

A proteção animal, particularmente centrada em uma ideia generalizada de violência e operada por meio do dispositivo da má consciência, é questionada por Descola (1998). Para ele, as manifestações de simpatia pelos animais são ordenadas em escalas de valor e espécies tidas como mais próximas dos humanos e que, em função de aspectos comportamentais ou 
faculdades cognitivas, são mais bem cotadas na hierarquia de interesse dos grupos protecionistas. Assim, os golfinhos, por exemplo, são estritamente protegidos em convenções internacionais, mas os harenques, as medusas ou as tênias não parecem dignos de atenção nem mesmo entre os militantes mais engajados desses movimentos. Para ele,

[...] o antropocentrismo, ou seja, a capacidade de se identificar com não humanos em função de seu suposto grau de proximidade com a espécie humana, parece assim constituir a tendência espontânea das diversas sensibilidades ecológicas contemporâneas, inclusive entre aqueles que professam as teorias mais radicalmente anti-humanistas (Descola 1998:25) .

O centro dessa crítica dirige-se a alguns neoecologismos que parecem converter povos autóctones na imagem perfeita de convívio harmonioso com a "sagrada mãe terra". Contudo, a predação animal entre esses povos, como é o caso dos Achuar da Amazônia equatorial, conflitua com a imagem do bom selvagem nutrida nesses movimentos. Assim, as práticas de relação com o animal costumam receber indulgências quando o tema é o estabelecimento de novos moralismos sobre a sua morte e o seu consumo. Neste caso, como mostra Descola $(1996,1998)$, não é raro esses povos serem moralmente condenados por alguns grupos que pregam a consciência ecológica e a libertação animal, por se utilizarem de práticas tradicionais de caça, que passam a ser vistas como uma forma de intervenção violenta em um ambiente pensado como natural. O que não se está considerando neste caso é que, tratados como natural, são na verdade ecossistemas historicamente modificados pela presença mutissecular desses povos, ou seja, já são ambientes antrópicos. Mais do que isso: o que alguns dos movimentos não têm percebido é que a relação de certos povos com o seu ambiente não se dá por meio da distinção ontológica que se opera entre nós, euro-americanos, que distribuímos em domínios distintos natureza e cultura e os humanos e os não humanos. Com isso, o caso amazônico, analisado por Descola, ajuda-nos a perceber, mesmo em outros contextos, que

[...] proteger os animais outorgando-lhes direitos - ou impondo aos humanos deveres para com eles - é apenas estender a uma nova classe de seres os princípios jurídicos que regem as pessoas, sem colocar em causa de maneira fundamental a separação moderna entre natureza e sociedade. A sociedade é fonte do direito, os homens o administram, e é porque são condenadas as violências para com os humanos que as violências em relação aos animais se tornam condenáveis. [...] Decidir tratar a natureza com respeito e benevolência supõe que a natureza exista - e também, sem dúvida, que tenha sido primeiramente maltratada. Quando a natureza não existe sob a forma de uma esfera autônoma, a relação com os animais só pode ser diferente da nossa, e a questão sobre matar um animal só pode se colocar em termos muito distintos daqueles que nos são familiares (1998:25, grifos meus). 
A organização da realidade a partir da antinomia natureza e cultura não é, para Descola (2005), um dado universal. O seu ponto de crítica em relação a esse cenário é o de: (i) a natureza não pode ser considerada como um dado (e nem uma categoria) universal sobre o qual se estabelecem descontinuidades culturais; e (ii) ela não pode ser tomada, de modo geral, como um domínio ontológico externo, distinto, do mundo dos humanos. Como ele mostra no seu trabalho de campo, entre os Achuar, a floresta não era um lugar prosaico - fonte de alimentos e de categorias - mas " [..] o palco de uma sociabilidade sutil [...]. O que chamamos aqui de natureza não é um objeto que deve ser socializado, mas o sujeito de uma relação social" (Descola 1996:246-247). Um desdobramento teórico dessa contestação da universalidade da antinomia natureza e cultura ganha forma em outro trabalho de Descola (2005), Par delà nature et culture. Nele, são amplamente caracterizados quatro modelos ontológicos instituídos a partir de modos de identificação entre humanos e não humanos, a saber: o animismo, o totemismo, o analogismo e o naturalismo. Este último, em particular, é oportuno para pensar o caso de Belinha, pois é com ele que Descola (2005) posiciona a cena filosófica ocidental, sobretudo aquela que se hegemoniza depois da Renascença. ${ }^{5}$

O naturalismo, em si, não é tomado como uma oposição entre natureza e cultura, particularmente entre o homem e a natureza, porém faz com que a interioridade do homem seja percebida como uma descontinuidade entre ele e o resto do mundo (que inclui seu próprio corpo). Trata-se de um movimento que pensa a universalidade da natureza como corolário de uma diversidade de culturas e, na reforma conceitual de Descola $(2005,2014)$, essa pensée moderne aparece como uma ontologia - um modo de ser - entre outros, e não a regra subjacente a todas elas.

Ao longo de sua obra, e particularmente na tetralogia Mitológicas, Lévi-Strauss valorizou sobremaneira o papel da natureza a partir da ideia de que o pensamento mítico organiza em sistemas significantes certos elementos empíricos. Porém, para Descola (2011:38), ainda que seja reconhecida a importância que certos traços relevantes do mundo empírico têm para a antropologia estruturalista de seu mentor, o ambiente físico foi relegado a um papel subalterno - o de oferecer ao pensamento mítico a matéria com que se alimenta. Nas suas palavras, " [...] a natureza torna-se como um gigantesco reservatório de propriedades observáveis dentro do qual o espírito terá toda a possibilidade de vir e colher objetos para convertê-los em signos". (Descola 2011:41). Assim, o autor não refuta esses contrastes que são universalmente percebidos nos estados da matéria, nas propriedades dos seres e nos modos de ação orgânicos, como o cheio e o vazio, o direito e o esquerdo, a vida e a morte, o quente e o frio, que oferecem tramas adequadas à organização de 
sistemas simbólicos (como foram para Lévi-Strauss). Contudo, ele afirma que “[...] nada autoriza a pensar que a antinomia natureza e cultura tenha sido, antes da época moderna, uma maneira comum de estruturar alguns desses contrastes entre traços salientes do mundo, mesmo num nível implícito" (Descola 2011:41).

Nesse caminho, a antinomia natureza e cultura não é um mau em si e é ingênua a sua estigmatização moral, como aquela operada por filosofias ecocêntricas, que insistem em atribuir a ela os diversos males da humanidade, como a expansão do colonialismo, a reificação das identidades sexuais, as distinções de classe ou as recentes declinações morais em favor dos animais. É preciso considerar que é sobre essa divisão que repousa a crença numa natureza que possui suas próprias leis e que assim permite o avanço das ciências. E nisso, a própria antropologia, longe de ter de se envergonhar de seu passado na esperança da expiação de seus pecados, precisa reconhecer que foi sobre essa divisão e a sua esperança no progresso da humanidade que também firmou suas próprias bases. A questão é que erramos ao supor que essa antinomia, produzida no contexto particular do Ocidente euro-americano e que organiza muita da sua realidade, ainda que não exclusivamente, seja uma fórmula adquirida por toda a experiência humana (Descola 2011).

No caso particular da relação com os animais no "mundo moderno" de hoje, é interessante notar que a morte de frangos ou de bois, que acontece em vertiginosa escala comercial a partir de indústrias de "produtos de origem animal", é induzida pela crença na natureza como uma externalidade e uma ilimitada fonte de recursos. Trata-se de uma razão comum na nossa ontologia naturalista, e que opera por meio de uma relação de consumo. Mas isso está longe de se aproximar da morte de animais em contextos produzidos a partir de outros modos de identificação, como aquele do caso Achuar, no qual há o entendimento de que os viventes estão no mundo em quantidade limitada. Ali, onde a relação se estabelece em regimes de reciprocidade, a morte de um animal que servirá como alimento é um evento complexo, sobretudo considerando que ele é um vivente com disposições morais contínuas aos humanos. Ela movimenta um sistema posicional, que é exemplificado por Descola (1998) como tipo de consciência do dano e das suas formas compensatórias que operam a relação, como no caso da criação dos filhotes de certos animais abatidos. Conforme suas palavras, 
[...] admitir que matar um animal que eu creio que vá reencarnar imediatamente não é matar, mas ser o agente de uma metamorfose; igualmente, matar um animal que eu creio poder substituir ao fim por almas humanas é menos matar do que aceitar o adiantamento de uma vida. A violência desaparece aqui não porque seja recalcada, mas porque não poderia ser efetiva em cosmologias concebidas como sistemas fechados nos quais a conservação do movimento dos seres e das coisas exige que as partes troquem constantemente de posição (Descola 1998:40).

Nessa referência multinaturalista de mundo, o animal consumido não está em um domínio do mundo externo àquele dos humanos, o que implica que ele não é um objeto predisposto. A sua eventual objetificação se dá à custa de responsabilidades e de interdições que precisam ser pensadas fora do nosso projeto moral, em que o animal é tomado, essencialmente, como uma externalidade ao mundo humano, dito social/cultural. Entre nós, situar o animal em um outro domínio de existência, como o da natureza pensada como externalidade, é um modo de facilitar essa objetificação, já que a distinção é vista como dada e independente de nossa vontade (Descola 1998). ${ }^{6}$

Desse modo, em contraponto, torna-se interessante notar que no contexto de pet shops e clínicas veterinárias - parte de um mundo pensado como multicultural - a ideia de natureza como essência e continuidade entre humanos e animais pesa. Nos casos de eutanásia que eu acompanhei na loja de Marcos, era interessante notar como os animais tinham a sua saúde e a sua doença testadas e atestadas por procedimentos especificamente padronizados pelos manuais clínicos da medicina veterinária que geravam diagnósticos universalizáveis. Esses protocolos eram soberanos em relação às moralidades produzidas no vínculo entre os animais e seus companheiros humanos, e esse processo concretizava uma espécie de performação da natureza, ao serem forjados na fisicalidade de cães e gatos, os elementos reconhecíveis pelos mecanismos valorizados da medicina veterinária (que, em essência, funciona como a humana). "Bons" ou "irrecuperáveis", eles se tornavam passíveis de tratamento ou de eutanásia, qual fosse o caso.

Medicalizar a morte de um animal, permitida pelo acionamento do argumento da sua falência biológica e pela mobilização da ideia de vida reduzida à funcionalidade clínica do corpo, transferia esse processo para a esfera da biologia e, com isso, diluía-se a culpa, uma vez que o diagnóstico era um prenúncio da ordem natural das coisas. O diágnóstico assumia a responsabilidade que os humanos haveriam de ter com seus animais. Além do mais, o diagnóstico é uma espécie de sócio do negócio, já que permite o encaminhamento de um animal para a morte que, nesse contexto, é um serviço pago e consideravelmente lucrativo. 
Em termos operacionais, a morte por eutanásia era provocada pela administração de uma dose três vezes maior do mesmo tipo de anestésico utilizado nas cirurgias. Após o "apagamento" total do animal, era-lhe injetado cloreto de potássio, para produzir a sua falência cardíaca. Essa era uma fórmula standard, atestava-me Marcos, e nisso, dizia ele, sua clínica acompanhava as tendências do seu setor. Porém, o problema se dava na continuidade do processo: o descarte. A cidade onde Marcos tinha sua clínica tinha pouco mais de 60 mil habitantes quando comecei a pesquisa e, apesar de naquela época haver cerca de 90 estabelecimentos do segmento pet, ela não contava com um cemitério para animais. Esses lugares, que nas ditas sociedades modernas são valorizados por permitirem variadas formas de lembrança e culto aos mortos, são, ainda que pouco confortável de se dizer fora do contexto biomédico, uma espécie de espaço sanitário.

Cemitérios destinados aos humanos sendo tratados a partir do ponto de vista da higiene é algo sobre o que não se fala, mas é um tema bastante valorizado no caso dos animais - ainda que esses espaços sejam tratados sob a forma de aterros sanitários. O acionamento da palavra cemitério aparece com mais frequência associado ao caso dos pets e não de quaisquer relações com os animais - não se diz cemitério de frangos ou de porcos quando mortos em função de controles populacionais ou pelos perigos da transmissão de zoonoses. O mesmo que se aplica nos casos de crematórios - em que os pets dispõem desse privilégio, enquanto os demais animais, suspeitos de serem vetores de doenças, não são cremados, mas incinerados.

No caso em questão, por não haver cemitério de animais na cidade e nem na região, após a eutanásia, os animais mortos eram embalados em sacos especiais e levados a um freezer para o congelamento, onde ficavam até serem coletados pelo caminhão de uma empresa responsável pelo recolhimento de restos hospitalares - ou seja, aquele lixo constituído por amputações e outros materiais retirados dos corpos de humanos em procedimentos cirúrgicos ou por causa de acidentes, como também os materiais relacionados, como seringas, luvas, lâminas etc. Há rigorosos procedimentos estabelecidos pela Agência Nacional de Vigilânica Sanitária (Anvisa) para a sua separação e destino, mas, grosseiramente, esse material é dividido em lixo do tipo A, que contém resíduos biológicos não tóxicos, mas potencialmente contaminantes, e em lixo do tipo $B$, que tem resíduos químicos de fármacos e outros materiais (Fonseca 2009). Desprovidos dos vínculos que supunham atributos culturais, aqueles pets - agora tecnicamente carcaças - eram incinerados com restos humanos em locais especializados. Depois disso, suas cinzas deveriam ser analisadas e encaminhadas a aterros que, igualmente, atendiam a normas específicas para este fim. Outros, com alguma sorte, eram levados para serem 
enterrados em algum local da propriedade de seus companheiros humanos, quando estes tinham casa em sítio ou em áreas menos urbanizadas, fora de raios de interdição sanitária. Com isso, na época, era interessante perceber o papel de uma associação de proteção ao animais, uma iniciativa civil bem estruturada, que reinvindicava na prefeitura um espaço para a construção de um cemitério na cidade. Ela se utilizava de uma estratégia curiosa, que consistia em sensibilizar o poder público com alertas sobre os perigos de zoonoses ou outras formas de contaminação dos humanos por causa daqueles animais. O cemitério, nessa situação, era lido sob a semântica de aterro sanitário, cuja urgência era fundamentada a partir da mobilização de argumentos biológicos com informações variadas sobre as contaminações de origem animal. Por outro lado, a associação também endossava as vozes dos companheiros dos pets, com o argumento de que esses animais também eram humanos e parte das famílias e não apenas carcaças perigosas; por isso, merecedores de respeito e de devoção. O cemitério, nesse registro, era um dever moral.

Mas o desfecho de Belinha foi outro - ainda não era chegado o momento de ela virar lixo do tipo A. Marcos tratou da cadela e, como ela era de bom porte, passando dos 15 quilos, o veterinário achou interessante colocá-la para estoque de sangue. Segundo ele, essa era uma prática comum, e até mesmo recomendada entre esses profissionais nos congressos em que ele costumava participar - a de se manter de dois a cinco animais nas clínicas ou hospitais para que se tornassem doadores de sangue (Apicella 2009). ${ }^{7}$ Marcos também me explicou que existem algumas alternativas artificiais para a substituição do líquido, mas que elas ainda eram muito caras e, dada a sua demanda, aqueles três animais podiam muito bem "dar conta do recado". ${ }^{8}$ Assim, a competência fisiológica de Belinha era fundamental para a manutenção da vida social de outros animais e, por conseguinte, dos negócios da clínica. Como dizia Marcos, justificando sua razão prática, "a saúde do sangue de Belinha é uma vida que ajuda outras vidas". Mais do que isso, o veterinário endossou uma ideia generalizada de modernidade em que a própria moral e o utilitarismo são corolários da natureza, sob a forma institucional da biologia.

A propósito, moralidades e ética como derivadas da biologia têm sido uma tendência que também se estabelece na crescente forma de controle das pesquisas que envolvem humanos, a partir das diretivas dos comitês de ética em pesquisa. A formação desses fóruns tem sido respaldada pelos debates da bioética que, no caso brasileiro, ainda que investida da interdisciplinaridade, tem sua direção forjada pela biomedicina, que ocupa nesse contexto um lugar central, fazendo com que a antropologia, a filosofia ou outras disciplinas ali presentes subsumam-se a ela (Duarte 2004; Cardoso 2013; Fonseca 2015). 
Já na pesquisa com animais, o fio condutor da crítica está no questionamento da hierarquia entre eles e os humanos, já que os coloca em posição de objeto instrumental. A experimentação animal é tema controverso há mais de um século, mas os argumentos mais valorizados atualmente vêm do casamento entre filosofia e neurociência, cujo debate ético tem sido norteado pelo tema da senciência (Levai \& Daró 2008; Prada 2008; Felipe 2008).

As agendas distintas dessa discussão são longas e intratáveis aqui, mas o que as assemelham àquela dos humanos é novamente o acionamento do argumento biológico - no caso, o da capacidade atestada por vias neurais, de que animais sentem dor. Fundada na senciência, a igualdade de direitos entre humanos e animais ganha fôlego nesse debate, de arrasto com um movimento emergente que se vale de uma noção de pessoa centrada no cérebro (Azize 2008, 2010; Pignarre 2006). Além do mais, a própria agenda protecionista animal oscila entre a reivindicação de direitos para os animais e a do tratamento dos animais como sujeitos de direito - e, neste caso, falamos de direitos civis estendidos, já que um tigre e um cão não participam no mesmo registro das associações com os humanos. Uns são animais demais para privilégios morais, enquanto outros são sociais demais para uma redução à natureza (Descola 1998; Descola \& Pálsson 2006; Bernardina 2006; Marguénaud 2010; Lestel 2011; Segata 2015b). Mais do que isso, nomes, sangue, roupas, proteínas, medicamentos, neurorreceptores de dor ou cálcio nos ossos, o que distingue e o que assemelha os humanos e os animais não têm mais como referência indivíduos inteiros, mas elementos partilháveis.

\section{Quando resta o animal}

A experiência de fazer uma etnografia no chamado segmento pet das clínicas veterinárias mostrou-me uma faceta - situacional e não exclusiva - da relação humano-animal em meios urbanos, que é capaz de tensionar o cuidado e a exploração. Por exemplo, aparar os pelos, cortar as unhas ou oferecer rações balanceadas são formas de produzir o convívio quando não se deseja que a mobília fique arranhada ou o chão do apartamento sujo com fezes de má consistência. Além disso, latir e rosnar podem ser índices de problemas psiquiátricos, como a ansiedade e a depressão - e que, por isso, precisam de diagnósticos precisos e de medicação (Segata 2015a). Com dinheiro, é possível escolher e comprar um filhote de determinadas características físicas, como a cor da pelagem e dos olhos ou atrofia das cordas vocais, que os fazem "geneticamente mudos" para não incomodarem no condomínio; e pode-se também torná-los distintos, com roupas, brincos, 
perfumes, enfim, como se diz, deixá-los "a cara do dono". Mas, além destes itens, o dinheiro também é necessário para a manutenção da invisibilidade do animal: as consultas têm preço, os tratamentos clínicos, cirúrgicos e medicamentosos não são baratos, como também as rações, as vacinas e tudo aquilo que ajuda a compor o tamanho, a qualidade (e a validade) de um pet.

Outra questão que merece atenção está naquilo que Digard (1999) caracterizou como "sistema domesticatório". Para ele, falar em domesticação, de um modo genérico e no sentido de um processo já acabado, é algo inadequado. Cada situação concreta da relação humano-animal, seja qual for o contexto, sugere uma domesticação singular ou eventual. No meu caso de pesquisa, isto se traduz em formas cada vez mais sofisticadas de invisibilização de comportamentos valorizados como animalescos, por meio de representações tecnocientíficas e de intervenções que embaralham o humano e o animal.

No caso particular de Belinha, o diagnóstico atuava na decodificação do animal em uma linguagem biomédica, criada e dominada pelo homem - um dispositivo que já foi amplamente discutido segundo a ideia de governo da vida (Foucault 2008; Rabinow 1996, 1999, por exemplo). No caso da relação humano-animal, esse processo de governo da vida transmite uma profunda impressão de que os animais precisam dos humanos, a ponto de realizarem a manutenção da humanidade, aquilo que Franklin (1999) chamou de "segurança ontológica", ou seja, a instabilidade classificatória do pet é porto seguro dos seus humanos.

Animais selvagens parecem ser os portadores de uma ontologia mais estável - a de autênticos animais da natureza, enquanto os demais são mais contingentes, sobretudo os últimos, os pets, mais próximos dos humanos e, por conseguinte, mais descaracterizados em sua essência (Lestel 2011; Fudge 2014; Digard 1990). Neste tipo de discurso, os animais tidos como selvagens seriam homogêneos e acomodados indistintamente entre classes e espécies, enquanto os pets seriam singularizados com seus nomes, seus tipos de expressão, seus perfumes, roupas ou estilo de vida (Ingold 2000). $\mathrm{Na}$ condição de pet, assemelhados aos humanos, alguns animais passam a ser vistos como portadores dos mesmos direitos, incluindo o direito de não se tornarem alimento e nem de serem objeto de violência. Porém, em alguns casos como o de Belinha, "destituída" de algumas dessas continuidades sociais - ela não tinha mais o lar, nem suas roupas e, principalmente, os seus humanos de estimação - restava-lhe apenas sua condição externa de recurso da natureza. 
Além de tais tópicos, importa frisar que, neste contexto de pesquisa, os processos domesticatórios são um bom negócio. O dinheiro tanto permite como limita a dita humanidade que transforma em pets esses animais e, por si só, esta é mais uma das muitas hierarquias suportadas por eles na relação e que oferece a seus humanos a sensação de estabilidade e de controle. Com isso, é interessante notar como são equalizados alguns limites, já que o sangue de boa qualidade de Belinha foi mais valorizado do que seus anos em companhia da família. No contexto de venda de serviços médico-veterinários, pagar pela vida do animal - e, em alguns casos, para que ele não fosse simplesmente um animal, dilemas morais e questões epistemológicas mobilizavam um conjunto amplo que me leva a sugerir que um pet é uma rede e não um animal em si.

As habilidades conjuntas que são desenvolvidas para a convivência, os artefatos técnicos, os diagnósticos, os tratamentos médicos e estéticos, as rações, o dinheiro, os direitos reivindicados e mais uma lista considerável de atores participam da sua constituição. A "estimação" não é uma propriedade dos entes - humanos, animais ou outros - mas da sua relação. Enfim, há camadas de complexidade que precisam ser rastreadas etnograficamente e nisto tem sido central o investimento antropológico em repensar seus domínios e suas ferramentas além do mundo do anthropos, mas da parte do mundo na qual humanos interatuam ou têm suas vidas cruzadas e coproduzidas com outros seres que também precisam aparecer em primeiro plano na etnografia (Descola \& Pálsson 2006; Kirskey \& Helmreich 2010).

Finalmente, ainda está viva em mim a lembrança de quando eu conheci Belinha. Ela se arrastava e cheirava mal porque costumava se deitar nas próprias fezes. Suas patas traseiras estavam quebradas e as da frente já não a sustentavam mais, o que a fazia ficar quase imóvel. Essa situação durou bem mais do que o tempo em que estive em trabalho de campo. O desejo de seus humanos pelo seu sacrifício era o compromisso com o fim do sofrimento, mas também com os gastos de seu tratamento e com o desconforto em ter que vê-la naquele estado. Como bem disse Bauman (2007) e antes dele Bruckner (1995), as coisas têm virado lixo muito cedo e a questão é que nessa perspectiva e no caso particular de Belinha, o vínculo que se pensou como descartado foi aquele dos humanos com ela; o fato é que poucos se perguntam se é fácil para o animal descartar-se dos seus humanos de estimação. Mais que isso, conforme uma provocação de Haraway (2008), "nenhuma razão é razoável o suficiente para tornar alguém matável" - mas, no caso de Belinha, também não era para mantê-la em sobrevida. O bom acolhimento e a comida abundante não justificavam o seu destino, pois o 
seu altruísmo em salvar outras vidas era uma escolha de Marcos, com as demandas comerciais da clínica. Todo o cálculo para a preservação da cadela não incluía a sua dor nos ossos, e nem toda a boa ração, com os complexos vitamínicos, e toda uma sorte de artifícios para mantê-la em bom estado eram suficientes para assegurar a sua dignidade. O que Marcos me fez conhecer na sua clínica não era mais a Belinha: restava ali pouco mais do que um saco de sangue saudável.

Recebido em 16 de agosto de 2016

Aprovado em 23 de novembro de 2016

Jean Segata é doutor em antropologia social e professor do Programa de Pós-Graduação em Antropologia Social da Universidade Federal do Rio Grande do Sul, Porto Alegre/RS, Brasil. E-mail: <jeansegata@ufrgs.br> 


\section{Notas}

1 Em se tratando do lugar ocupado pelo tema da relação humano-animal na antropologia, a crítica tem sido centrada no modo como tradicionalmente temos definido a disciplina como o estudo da humanidade. Isso torna autêntica a ideia generalizada no Ocidente de que os animais sejam vistos como recursos que figuram como parte de ecossistemas antropicamente centrados - a natureza, e nela incluídos os animais, é uma externalidade objetificável. Além disso, esse modelo costuma reduzir a agência ao domínio humano. Como provoca Noske (2008:22): "os animais costumam ser retratados sob a forma de objetos passivos - eles são tratados, pensados e sentidos. Longe de serem considerados agentes ou sujeitos de direito, os animais são praticamente ignorados pelos antropólogos. Eles e suas relações com os seres humanos tendem a ser considerados indignos de interesse antropológico". Na França, um recente colóquio tratou da emergência dessas discussões a partir da ideia de uma virada animalista na antropologia [Un tournant animaliste en anthropologie?]. Em pauta, estava a recente conjunção entre os avanços das ciências da vida e suas aproximações com a etologia e a cognição, a revisão de clássicas discussões filosóficas sobre o homem e os animais e as sensibilidades produzidas em função de recentes movimentos protecionistas. "Até que ponto 'o animal' pode contribuir para o conhecimento dele mesmo e da diversidade e da complexidade de sua coexistência com as sociedades humanas? Os animais formam um campo de estudos na antropologia? Quais são os recursos metodológicos para o que se tem chamado de 'questão animal'? Essas foram algumas das questões que nortearam os debates do colóquio, fazendo coro às críticas em torno do desinteresse da disciplina pela "questão animal". O seu programa completo está disponível em < http://las.ehess.fr/index.php?2104>. Acesso em nov. 2014. Para uma contundente crítica às discussões levantadas nesse colóquio, ver o artigo de Jean-Pierre Digard (2012), publicado na revista L'Homme, com o título provocativo de "Le tournant obscurantiste en anthropologie" [A virada obscurantista na antropologia]. Finalmente, é importante frisar que o Human-animal studies é um amplo campo interdisciplinar, que fora do registro das ciências naturais, inclui a sociologia, a história, a filosofia, a psicologia, a literatura e a antropologia. Para boas resenhas do campo, ver Flynn (2008), Taylor e Signal (2011), DeMello (2012) e Taylor (2013). Particularmente, eu tenho me centrado na produção antropológica sobre o tema, em especial, nos meios urbanos. Apesar de não haver uma agenda bem definida na disciplina, trabalhos como os de Vialles (1987), Ingold (1988), Willis (1990), Digard (1990, 1999), Bernardina (2006), Keck (2010), Hurn (2012), Vicart (2014) são pioneiros e orientam grande parte dos interessados no campo. No caso brasileiro, grupos de trabalho e mesas redondas em eventos como a RBA, REA-ABANNE, REACT, RAM e ANPOCS, grupos de pesquisa como o Espelho Animal do PPGAS-UFRGS e dossiês temáticos em periódicos, como a Revista Anthropológicas, o Anuário Antropológico, a Revista Iluminuras, a revista Vibrant e a R@U - Revista de Antropologia da UFSCar, indicam a expansão do campo. Além disso, é notável que nos últimos anos teses e dissertações tenham sido produzidas a partir de pesquisas sobre este tema (Calmon de Oliveira 2006; Segata 2012; Matos 2012; Pastori 2012; Sordi 2013; Leal 2014; Franco 2015; Teixeira 2015), sendo algumas delas já publicadas (Sá 2013; Vander Velden 2012; Süssekind 2014). Cabe frisar também que autores como Philippe Desco- 
la e Eduardo Viveiros de Castro são referências sempre pertinentes nesse campo, particularmente sobre as questões epistemológicas que ele suscita. Eles são casos emblemáticos que ilustram tendências de trabalhos da etnologia ameríndia, na qual o animal é fundamental para estabelecer os contornos da humanidade, sobretudo em regimes em que a predação é um dispositivo relacional e constitutivo (Descola 2005; Viveiros de Castro 2002, 2009). Entre muitos exemplos, estão os trabalhos de Fausto (2001), Lima (2005), Bonilla (2007) e Garcia (2011). Para a discussão dos dilemas morais na relação humano-animal, Lewgoy et al. (2015) apresentam uma densa resenha da temática a partir de uma etnografia do universo da proteção animal em Porto Alegre/RS.

2 Certo é que o envelhecimento e o debate sobre a eutanásia - em si ou combinados - são desafios. No contexto humano atual, conforme já problematizou Rifiotis (2007), o ícone disciplinar da gerontologia não coincide com o seu "objeto preferencial" - o idoso, aposentado, com necessidades de proteção e apoio - mas sim, aquele jovem velho, "com recursos suficientes para custear a sua medicalização e lazerização" (Rifiotis 2007:143). Uma pista interessante é a de se avaliar quanto a noção de pessoa centrada no individualismo como valor (Duarte 1986) também colide com as políticas de longevidade, já que a ideia de cuidado conflitua com a autonomia valorizada nesse âmbito.

3 Eu acompanhei o caso de Belinha entre 2007 e 2009, durante a minha pesquisa de campo do doutorado (Segata 2012). Gostaria de agradecer às inúmeras contribuições que recebi nas oportunidades em que ele foi discutido. Isso aconteceu em seminários com alunos da pós-graduação da UFSC, da UnB, da UFRN e da UFMT, no ciclo de debates Universidade do Futuro do ILEA-UFRGS e nas Tardes Antropológicas do PPGAS-UFPB. Essas atividades não seriam possíveis sem o apoio fundamental de Theophilos Rifiotis, Bernardo Lewgoy, Juliana Abonizio, Maristela Andrade e Carlos Sautchuk. Igualmente agradeço ao CNPq pelos meios que tornam viáveis a continuidade de minhas pesquisas nesse campo, a partir do projeto "Como os animais fazem a cidade" (Chamada MCTI/CNPq/Universal 14/2014).

4 Eu também falei de Belinha em uma das Jornadas de Antropologia da UFSC em 2008 e em 2009, na Reunião de Antropologia da Ciência e Tecnologia/ReACT, que aconteceu na UFMG. Ainda eram as primeiras impressões e, naquela época, eu estava interessado na mediação tecnológica da relação - como se operavam as coletas e as transfusões de sangue, os diagnósticos e, acima de tudo, os tipos de equipamentos que eram empregados naquelas situações - que aproximavam e distanciavam humanos e animais. As reações sobre sua história variavam entre a curiosidade e a indignação ainda que, quase sempre, combinassem em reprovação. Na UFMG, uma colega de Grupo de Trabalho que antes de mim falara sobre os massacres nas Américas, liderados por Francisco Pizarro ou Hernán Cortéz, dizia-me que aquilo que faziam com Belinha era uma espécie de barbárie ou qualquer coisa desumana. Apesar da proporção, objetivo e distância histórica entre os eventos que apresentamos, ela não se rogou a fazer alguma equivalência naquela hora. Um ano antes, na UFSC, em um tom parecido, eu ouvira uma espécie de conselhos para a luta contra todo esse "absurdo" praticado contra um animal, sobretudo cobranças de que a antropologia deveria se manifestar contra os casos em que a "dignidade humana de um animal" estivesse em risco (Segata 2014). 
5 O animismo e o totemismo já eram conhecidos na antropologia para tratar dos modos como se identificam os humanos e outros seres - como as plantas, os animais, os fenômenos climáticos, os espíritos ou os artefatos. Contudo, esses modos de pensar a identificação passaram a ser contestados na primeira metade do último século, sob a acusação de vestígios do evolucionismo na disciplina. Tratados na forma de crenças, eram compreendidos como um traço característico de povos cuja mente operava sem a razão (Charbonnier 2015). Contudo, Descola (2005) reposiciona o animismo e o totemismo em termos de identificação de si e do mundo distintos dos nossos, porém não inferiores ou menos complexos (em outros termos, que caracterizam diferentes ontologias). Em termos gerais, no animismo, o humano e o não humano são distinguidos por meio de suas características físicas, e o estabelecimento da identificação é sustentada pela valorização de uma continuidade interior: animais, plantas, objetos têm disposições próprias de uma "moral" tipicamente humana. Enquanto isso, no totemismo, amplia-se o escopo de partilha entre humanos e não humanos, sobretudo acentuando as continuidades físicas, como a destreza, a sutileza ou a força dos corpos, em detrimento de uma descontinuidade interior. Já o analogismo responde por um sistema no qual os humanos pensam que tudo o que compõe o mundo, sendo elementos físicos ou morais, são descontínuos ou diferentes - tudo é singularidade. Nesse modo ontológico, impera a fragmentação generalizada que se organiza apenas por correspondências pontuais, como no caso da Scala Naturae.

6 Em outras situações cotidianas, a economia da moralidade também traz complexidades, como em muitas daquelas em que operações policiais resultam na perda de vidas. Em cenários cada vez mais comuns, que denotam uma evidente execução de suspeitos, tais operações são consideradas pelo Estado e, sobretudo, pela opinião pública como bem sucedidas, na medida em que se aciona a ideia de que "bandidos" foram tirados de circulação. O suspeito que é morto não é um ente que está em um domínio distinto de existência de quem o matou, mas sua objetificação é construída com o acionamento da própria palavra bandido, que funciona como produtora de um abjeto. Ao invés de prender, inquerir, acusar, julgar, permitir defesa, apenar e ressocializar, tornar alguém matável sob a fórmula de bandido é um exemplo que tem se tornado cada vez mais trivial das maneiras como produzimos dispositivos de distanciamento moral, que expurgam e invisibilizam a violação de direitos. Sobre o debate a respeito de um conceito de sujeito que possa servir como fundamento para a ação e a responsabilização moral, ver o recente trabalho de Butler (2015).

7 Sobre doações/transfusões de sangue em cães e gatos, ver < http://www. saudeanimal.com.br/ artig160.htm>. Acesso em: 1\%08/ 2011.

8 Nas vezes em que falei de Belinha, nos eventos que citei anteriormente, houve opiniões de colegas das ciências sociais e da antropologia que chegaram a sugerir que o uso de vira-latas para serem doadores de sangue em favor de salvar os animais de raça trazidos à loja era mais uma afirmação dos privilégios de uma minoria distinta. A analogia se dava nos termos de classe social - os vira-latas e outros animais comuns tratados como funcionais, que equivaleriam aos assalariados e pobres que, numa linguagem já bem enviezada do marxismo, se alienam ao venderem/ou serem forçados a oferecer sua força produtiva, transformando-se em simples ferramenta para a manutenção e o desenvolvimento de uns poucos, os patrões (neste caso, os animais 
de estimação com estatuto de humanidade). "Ninguém questiona isso", provocavam, "porque já temos inculcado em nós essa visão dos que têm valor e dos que não têm - e de quem trabalha para quem, quem é gente e quem não é". Outra questão que se tocava em tom delicado, nessa estocagem de sangue, era a de que se tratava de fazer uso de cães que não tinham uma raça definida. Eu questionei Marcos sobre isso - até mesmo em tom de brincadeira - se ele não haveria tido problemas com alguns dos donos de animais de raça, que por ventura descobrissem que, no caso da necessidade de uma transfusão sanguínea, o líquido utilizado viria de outros, sem raça definida e sem pedigree. Para Marcos (e para a Medicina Veterinária), aquilo não fazia diferença - no entanto, ele pediu que eu não tocasse nesse assunto com os clientes - afinal, isso já havia sido motivo de constrangimento em um episódio isolado e sobre o qual Marcos apenas me disse que nunca havia pensado que isso pudesse ser um problema, que chegasse, inclusive, às representações jurídicas. Ele balançava a cabeça, reprovando aquilo que ele dizia ser a mais pura ignorância - o fato de haver pessoas que acreditavam que se têm saquinhos de sangue na geladeira da clínica, com a raça discriminada em rótulos, como o sangue de humanos, com suas tipagens marcadas. A questão é que no contexto da criação de animais de raça, Calmon de Oliveira (2006), em sua etnografia sobre "homens e cães", mostrou como a pureza - em seus aspectos genotípicos e fenotípicos e o pedigree do animal - são elementos centrais para o grupo que ela pesquisou, o de criadores de cães, muitos deles campeões, que são levados às exposições de beleza. Para ela, "[...] como cães de raça campeões são vistos pelos criadores como obras de arte raras [...]", saber sobre eles e suas raças é um conhecimento distintivo do grupo pesquisado, como aquilo que compõe o que Bourdieu (2007) chamou de capital simbólico: a raça do cão, sua genealogia e pedigree diziam muito sobre seus donos - seus meios e posição social. E o sangue tem aí um papel fundamental - especialmente na composição do imaginário ocidental sobre o parentesco ou a pureza racial - é o "puro sangue" que faz a diferença - o sangue azul, o sangue bom "daquela matriz". Marcos me explicou que tecnicamente não haveria problemas no uso de "um sangue qualquer", pois a compatibilidade entre os cães não é medida da mesma forma que a humana. Segundo ele, apenas em algumas exceções há a rejeição - que se pode prevenir a partir de um teste simples, em que são misturados em um tubo de ensaio uma amostra do sangue do doador com a do receptor, que não podem coagular, depois de sacudido o recipiente por alguns segundos. Mas antes que alguém pudesse achar que se botar sangue de um vira-lata num Dálmata fizesse com que ele perdesse as suas manchas no pelo ou a própria raça, Marcos achou melhor censurar os meus comentários sobre o tema. 


\section{Referências bibliográficas}

APICELLA, Camila. 2009. Transfusão sanguínea em cães. Monografia de Graduação em Medicina Veterinária, Centro Universitário das Faculdades Metropolitanas Unidas.

AZIZE, Rogério. 2008. "Uma neuro-weltanschauung? Fisicalismo e subjetividade na divulgação de doenças e medicamentos do cérebro". Mana. Estudos de Antropologia Social, 14(1):7-30.

. 2010. A nova ordem cerebral: a concepção de "pessoa" na difusão neurocientífica. Tese de Doutorado, Museu Nacional, Programa de Pós-Graduação em Antropologia Social, Universidade Federal do Rio de Janeiro.

BAUMAN, Zygmunt. 2007. Vida líquida. Rio de Janeiro: Zahar.

BERNARDINA, Sergio Dalla. 2006. L'éloquence des bêtes: quand l'homme parle des animaux. Paris: Métallié.

BRUCKNER, Pascal. 1995. La tentation de l' innocence. Paris: Grasset.

BOURDIEU, Pierre. 2007. A distinção: crítica social do julgamento. São Paulo: Edusp/ Porto Alegre: Zouk.

BUTLER, Judith. 2015. Relatar a si mesmo: crítica da violência ética. São Paulo: Autêntica.

BONILLA, Oiara Lydie. 2007. Des proies si desirables: soumission et prédation pour les Paumari d'Amazonie brésilienne. Thèse de doctorat, École des Hautes Études en Sciences Sociales, Paris, França.

CALMON DE OLIVEIRA, Samantha Brasil. 2006. Sobre homens e cães: um estudo antropológico sobre afetividade, consumo e distinção. Dissertação de Mestrado, Universidade Federal do Rio de Janeiro.
CARDOSO, Marina. 2013. "Etnografia entre 'éticas': ética e pesquisa com populações indígenas". In: Cynthia Sarti \& Luiz Fernando Dias Duarte (orgs.), Antropologia e ética: desafios para a regulamentação. Brasília-DF: Edições ABA. pp. 131-171.

CARCIOFI, Aulus Cavalieri \& JEREMIAS, Juliana Toloi. 2010. "Progresso científico sobre nutrição de animais de companhia na primeira década do século XXI". Revista Brasileira de Zootecnia, 39:35-41.

CARCIOFI, Aulus Cavalieri. 2014. "Osteodistrofias - como evitá-las". Disponível em: http://www.smcpa. org.br/pdf/Osteodistrofias_caes.pdf. Acesso em 21/03/2014.

CHARBONNIER, Pierre. 2015. La fin d'un grand partage: nature et société, de Durkheim à Descola. Paris: CNRS Éditions.

DEMELLO, Margo. 2012. Animals and society: an introduction to humananimal studies. New York: Columbia University Press.

DESCOLA, Philippe. 1996. "Ecologia e cosmologia". In: Edna Castro \& Florence Pinton (orgs.), Faces do trópico úmido: conceitos e questões sobre desenvolvimento e meio ambiente. Belém: Cejup. pp. 243-261. . 1998. "Estrutura ou sentimento: a relação com o animal na Amazônia". Mana. Estudos de Antropologia Social, 4(1):23-45. . 2005. Par-delà nature et culture. Paris: Gallimard. . 2011. "As duas naturezas de Lévi -Strauss". Sociologia \& Antropologia, 01-02: 35-51.

. 2014. La composition des mondes: entretien avec Pierre Charbonnier. Paris: Flammarion. 
DESCOLA, Philippe \& PÁLSSON, Gísli. 2006. "Introducción". In: Naturaleza y sociedad: perspectivas antropológicas. Coyoacán: Siglo XXI. pp. 11-36.

DIGARD, Jean-Pierre. 1990. L'homme et les animaux domestiques: anthropologie d'une passion. Paris: Fayard. 1999. Les français et leurs animaux: ethnologie d'un phénomène de société. Paris: Fayard. . 2012. "Le tournant obscurantiste en anthropologie: de la zoomanie à l'animalisme occidentaux". L'Homme, 203-204:555-578.

DUARTE, Luiz Fernando Dias. 1986. Da vida nervosa nas classes trabalhadoras urbanas. Rio de Janeiro: Jorge Zahar Editor/ CNPq. . 2004. "Ética de pesquisa e 'correção política' em antropologia". In: Ceres Víctora; Ruben George Oliven; Maria Eunice Maciel \& Ari Pedro Oro (orgs.), Antropologia e ética: o debate atual no Brasil. Niterói: EdUFF. pp. 125-130.

FAUSTO, Carlos. 2001. Inimigos fiéis: história, guerra e xamanismo na Amazônia. São Paulo: Edusp.

FELIPE, Sônia. 2008. "O estatuto dos animais usados em experimentos: da negação filosófica ao reconhecimento jurídico". In: Thales Tréz (org.), Instrumento animal: o uso prejudicial de animais no ensino superior. Florianópolis: Editora da UFSC. pp. 65-110.

FLYNN, Clifton (ed.). 2008. Social creatures: a human and animal studies reader. New York: Lantern Books.

FONSECA, Janaína Conrado. 2009. Manual para gerenciamento de resíduos perigosos. São Paulo: Cultura Acadêmica.

FONSECA, Claudia. 2015. "Situando os comitês de ética em pesquisa: o sistema CEP (Brasil) em perspectiva". Horizontes Antropológicos, 21(44):333-369.
FOUCAULT, Michel. 2008. Nascimento da biopolítica. São Paulo: Martins Fontes.

FRANCO, Ana Paula Perota. 2015. Humanidade estendida: a construção dos animais como sujeitos de direitos. Tese de Doutorado, Universidade Federal do Rio de Janeiro.

FRANKLIN, Adrian. 1999. "Pets and modern culture". In: Animals \& modern cultures: a sociology of human-animal relations in modernity. London: Sage. pp. 84-15.

FUDGE, Erica. 2014. Pets. Buenos Aires: Paidós.

GARCIA, Uirá. 2011. Karawara: a caça e o mundo dos Awá-Guajá. Tese de Doutorado, Universidade de São Paulo.

HARAWAY, Donna. 2008. When species meet. Minneapolis: University of Minnesota Press.

HURN, Samantha. 2012. Human and other animals: cross-cultural perspectives on human-animal interactions. London: Pluto Press.

INGOLD, Tim (ed.). 1988. What is an animal? London: Routledge. . 2000. "A circumpolar night's dream". In: The perception of the environment: essays in livelihood, dwelling and skill. London: Routledge. pp. 89-110.

KECK, Frédéric. 2010. Un monde grippé. Paris: Flammarion.

KIRSKEY, Eben \& HELMREICH, Stefan. 2010. "The emergence of multispecies ethnography". Cultural Anthropology, 25(4):545-576.

KULICK, Don. 2009. "Animais gordos e a dissolução das fronteiras entre as espécies". Mana. Estudos de Antropologia Social, 15(2):481-508.

LATOUR, Bruno. 2001. A esperança de Pandora: ensaios sobre a realidade dos estudos científicos. Bauru: EdUSC. 
LEAL, Natacha Simei. 2014. Nome aos bois: zebus e zebuzeiros em uma pecuária brasileira de leite. Tese de Doutorado, Universidade de São Paulo.

LESTEL, Dominique. 2002. As origens animais da cultura. Lisboa: Instituto Piaget.

. 2011. "A animalidade, o humano e as 'comunidades híbridas'". In: Maria Esther Maciel (org.), Pensar/ escrever o animal, ensaios de zoopoética e biopolítica. Florianópolis: Editora da UFSC. pp. 23-54.

LEVAI, Laerte \& Daró, Vânia. 2008. "Experimentação animal: histórico, implicações éticas e caracterização como crime ambiental". In: Thales Tréz (org.), Instrumento animal: o uso prejudicial de animais no ensino superior. Florianópolis: Editora da UFSC. pp. 43-64.

LEWGOY, Bernardo et al. 2015. "Domesticando o humano: para uma antropologia moral da proteção animal". ILHA - Revista de Antropologia, $17(2): 75-100$.

LIMA, Tania Stolze. 2005. Um peixe olhou para mim: o povo Yudjá e a perspectiva. São Paulo: Editora Unesp.

MAUSS, Marcel \& HUBERT, Henry. 2005. Sobre o sacrifício. São Paulo: Cosac \& Naify.

MARGUÉNAUD, Jean-Pierre. 2010. "Déverrouiller le débat juridique". In: Jean Birnbaum (dir.), Qui sont les animaux? Paris: Folio. pp. 151-165.

MATOS, Liziane Gonçalves de. 2012. Quando a "ajuda é animalitária": um estudo antropológico sobre sensibilidades e moralidades envolvidas no cuidado e proteção de animais abandonados a partir de Porto Alegre/ RS. Dissertação de Mestrado, Universidade Federal do Rio Grande do Sul.
NOSKE, Barbara. 2008. "The animal question in anthropology". In: Clifton Flynn (ed.), Social creatures: $a$ human and animal studies reader. New York: Lantern Books. pp. 22-28. PASTORI, Érica. 2012. Perto e longe do coração selvagem: um estudo antropológico sobre animais de estimação em Porto Alegre, Rio Grande do Sul. Dissertação de Mestrado, Universidade Federal do Rio Grande do Sul.

PIGNARRE, Philippe. 2006. Les malheurs des psys: psychotropes et médicalisation du social. Paris: La Découverte.

PRADA, Irvênia. 2008. "Os animais são seres sencientes". In: Thales Tréz (org.), Instrumento animal: o uso prejudicial de animais no ensino superior. Florianópolis: Editora da UFSC. pp. 15-41.

RABINOW, Paul. 1996. Making PCR: a story of biotechnology. Chicago: The University of Chicago Press. . 1999. "Artificialidade e Iluminismo: da sociobiologia à biossocialidade". In: João Biehl (org.), Antropologia da razão: ensaios de Paul Rabinow. Rio de Janeiro: Relume-Dumará. pp. 135-158.

RIFIOTIS, Theophilos. 2007. "O idoso e a sociedade moderna: desafios da gerontologia". Pro-Posições, 18(1):137151.

SÁ, Guilherme. 2013. No mesmo galho: antropologia de coletivos humanos e animais. Rio de Janeiro/Brasília: 7 Letras/Editora da UnB.

SEGATA, Jean. 2012. Nós e os outros humanos, os animais de estimação. Tese de Doutorado, Universidade Federal de Santa Catarina. . 2014. "A agência de um projeto, o paraíso vegetariano e outros inconvenientes com a humanidade dos animais de estimação na antropologia". Revista Anthropológicas, 24:45-65. 
2015a. "La cosmopolitique de la dépression: biosocialité dans une ethnographie multi-espèces". Vibrant, 12:290-320.

2015b. "Gatos fidalgos, cálculos renais e as humanidades de animais de estimação". Vivência, 1:85-104.

SORDI, Caetano. 2013. De carcaças e máquinas de quatro estômagos: estudo das controvérsias sobre o consumo e a produção de carne no Brasil. Dissertação de Mestrado, Universidade Federal do Rio Grande do Sul.

SÜSSEKIND, Felipe. 2014. O rastro da onça: relações entre humanos e animais no Pantanal. Rio de Janeiro: 7 Letras.

TAYLOR, Nik. 2013. Humans, animals and society: an introduction to human-animal studies. New York: Lantern Books.

. \& SIGNAL, Tania (eds.). 2011. Theorizing animals: re-thinking humanimal relations. Boston: Brill.

TEIXEIRA, Ivana dos Santos. 2015. A terapia assistida por Animais como uma forma de associação: um estudo antropológico sobre a relação humano-animais na promoção da saúde humana, no Brasil. Tese de Doutorado, Universidade Federal do Rio Grande do Sul.
VANDER VELDEN, Felipe Ferreira. 2012. Inquietas companhias: sobre animais de criação entre os Karitiana. São Paulo: Alameda.

VIALLES, Noëlie. 1987. Le sang et la chair: les abattoirs des Pays de l'Adour. Paris: Éditions de la Maison des Sciences de l'Homme.

VICART, Marion. 2014. Des chiens auprès des hommes: quand l'anthropologue observe aussi l'animal. Paris: Pétra.

VIVEIROS DE CASTRO, Eduardo. 2002. "O nativo relativo". Mana. Estudos de Antropologia Social, 8(1):113-148. . 2009. Métaphysiques cannibales: lignes d'anthropologie post-structurale. Paris: PUF.

WILLIS, Roy (ed.). 1990. Signifying animals: human meaning in natural world. London: Routledge. 


\section{QUANDO O ANIMAL DURA MAIS QUE A ESTIMAÇÃO}

\section{Resumo}

O estudo das relaçóes humanoanimal tem formado um campo que ganha boa expressão na antropologia contemporânea. Ele se desenvolve a partir de duas frentes de discussão que se complementam - uma política e outra epistemológica. A primeira envolve ativismos e novos movimentos sociais em torno de direitos e de moralidades dos animais, enquanto a outra passa a questionar e a reposicionar qualidades e distinções entre eles e os humanos. Neste trabalho, eu procuro abordar estas questões por meio de um dilema moral que envolve uma cadela velha e doente, que depois de uma vida como parte de uma família humana, foi encaminhada para eutanásia e terminou transformada em estoque de sangue de uma clínica veterinária. Fisicalidade e moralidade são mobilizadas de forma contingente nesse contexto de pesquisa, tanto para equivaler e diferenciar humanos e animais como para compor e decompor um animal de estimação.

Palavras-chave: Relação humanoanimal, Animais de estimação, Humanidade/animalidade, Naturalismo.

\section{CUANDO EL ANIMAL DURA MÁS QUE LA ESTIMACIÓN}

\section{Resumen}

El estudio de las relaciones entre humanos y animales se ha conformado como un campo prolífico en la antropología contemporánea. Se desarrolla en dos frentes de discusión que se complementan entre sí - uno político y otro epistemológico. El primero consiste en el activismo y los nuevos movimientos sociales en torno a los derechos y las moralidades de los animales, mientras que el otro va a cuestionar y cambiar la posición de las cualidades y las diferencias entre ellos y los humanos. En este trabajo, trato de abordar estas cuestiones a través de un dilema moral relacionado con una perra vieja y enferma, que después de una vida como parte de una familia humana, fue enviada a la eutanasia y terminó convertida en fuente de suministro de sangre de una clínica veterinaria. Lo físico y lo moral se movilizan de manera contingente en este contexto de investigación, tanto para igualar y diferenciar a los humanos y animales cuanto para componer y descomponer una mascota.

Palabras clave Relaciones entre humanos y animales, Mascotas, Humanidad/ animalidad, Naturalismo. 
WHEN THE PET OUTLASTS COM PANIONSHIP

\section{Abstract}

The study of human-animal relations has been conspicuous in contemporary anthropology. It has developed along two complementary fields, one political and the other epistemological. The first involves activism and new social movements concerning the rights and moralities of animals, while the other questions and reframes the distinctions between animals and humans. In this article, I address these issues by investigating a moral dilemma involving an old, sick dog that, after spending its life as part of a human family, had to be euthanized and ultimately became blood stock for a veterinary clinic. Physicality and morality are mobilized contingently in this research context, both to identify and differentiate humans and animals and to compose and decompose a pet. Key words Human-animal relations, Pets, Humanity/animality, Naturalism. 